\title{
Journal of \\ MENTAL HEALTH and ADDICTION NURSING
}

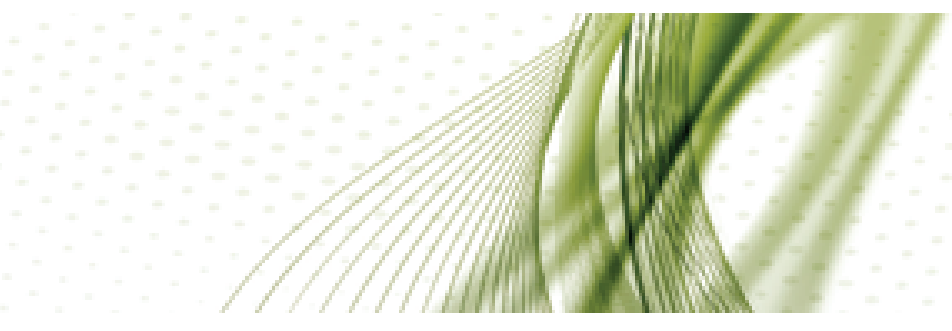

DOI: $10.22374 /$ jmhan.v3i1.38

\section{A CLINICAL OBSERVATION OF SPIRITUAL PHENOMENA DURING TREATMENT OF THE CHEMICAL DEPENDENCY POPULATION}

Susan Kaiser

*Corresponding Author: skkaiser@msn.com

\begin{abstract}
This article reports the observations of one clinician working with the chemical dependency (CD) population in the outpatient format. Spiritual phenomena and positive changes resulting thereof in the recovery process of select patients made a great impression upon this writer. These spiritual changes were not treatment-induced or patient determined. Rather the spiritual phenomena observed were select and sudden, individual, personal and included remorse with the hope of restitution on the part of the subject. This observation included further study citing research, discussion, and conclusions. Spiritual practices are linked to better remission outcomes, but must also include voluntary participation on the part of the CD client. Further study and improved awareness of the importance of the Spiritual in the treatment of the CD population is needed.
\end{abstract}

Key words: Addiction, Spirituality, Social Bonds, Relapse

"Turning East" is a term coined by this writer to describe an unpredictable Spiritual phenomenon, observed in a few select clients, while working with the chemically dependent population in the outpatient format. The phenomenon discussed herein is an inexplicable positive change of heart, and emotional direction, observed in member(s) of a treatment group. This positive change included a deeper awareness expressed for the problems and emotional pain caused those close to the subject as a result of his/ her addiction behaviors. The awareness expressed was sorrowful and remorseful, leading to a greater determination to remain faithful to the recovery process and long-term sobriety, as well as the moral law. This phenomenon was not deliberately induced or connected to any observable treatment activity within the control of management. Furthermore, this startling change of "Turning East" was observed in the first three months of substance abuse abstinence, a critical time period in early recovery, when early substance abstinence results in brain changes directed at reaching baseline. ${ }^{1}$ This early recovery phase in treatment is usually not voluntary but a condition imposed by legal requirement.

What is not expected (in early abstinence phase of recovery) is a form of sudden spiritual awakening, with insight, sorrow and regret for injury to others as a result of substance misuse, and a more objective

J Mental Health Addic Nurs Vol 3(1):e32-e37; November 21, 2019.

This article is distributed under the terms of the Creative Commons Attribution-Non Commercial 4.0 International License. CKaiser 2019. 
understanding of consequences resulting from these choices, with the hope that restitution could be accomplished. The select clients who demonstrated this intense change coined "Turning East" made a remarkable impression upon this writer.

However, this author asserts that the understanding of "Turning East" can also be expanded to include all members of the chemical dependency (CD) population who obtain long-term sobriety. For those who make the effort to remain substance abstinent, and faithfully follow treatment recommendations and protocol, longterm sobriety and recovery is also remarkable. This form of recovery also requires a response to internal spiritual promptings, although less dramatic and over a much longer recovery period.

Spiritual, in terms of this writing, is used to mean more than not organic or material. The spirit is recognized as a higher level of existence, above the laws of physical creation. An excerpt from the documents of Vatican II is quoted regarding the spirit of the human person. This selection is based upon the beauty and precision of the language quoted, "With his openness to truth and beauty, his sense of moral goodness, his freedom and the voice of his conscience, with his longings for the infinite and happiness, man questions himself about God's existence. In all this he discerns signs of his spiritual soul. The soul, the 'seed of eternity' we bear in ourselves, irreducible to the merely material, can have its origin only in God."2

\section{DISCUSSION}

Anyone who ever worked with the chemically dependent $(\mathrm{CD})$ population has experienced how impossible it is to predict which clients will gain long-term substance abstinence and sobriety and those who will not. Early predictions about individual treatment responses are impossible with this population. However, models for assessment of client strengths, resources and readiness for change as well as useful interview techniques are evolving and frameworks to address the many other factors linked to gaining sobriety. For example, many factors pertinent to recovery and sobriety, including addressing the spiritual, are discussed by William Miller in his book Treating Addiction. ${ }^{3}$

\section{EXAMPLES}

Examples of "Turing East" include the following: Example one, A middle-aged Hispanic male, previously quiet during group sessions and appearing withdrawn, defensive or disengaged, informed this author that he needed to talk. After entering the office and shutting the door, he tearfully began to explain the realization of the magnitude of his failure as a father to his young daughter. He described instances of impatience to this young daughter and his regret for reacting so harshly. He also verbalized regret about his lengthy absences from her life. He described awareness that his actions may have imposed long-term damage to his daughter and to their relationship.

Conclusion: This kind of piercing and intact insight, about the negative long-term impact of actions under the influence of substance misuse, is rare overall, and unexpected within the early phases of substance misuse withdrawal.

Example two, a young woman, of European genetic lineage, attended her intake appointment for legally required outpatient chemical dependency treatment, having been driven to the appointment by a friend. The information accumulated from the intake appointment included a history of such severe substance misuse this author was prepared to never see this patient again, alive. This patient did attend treatment sessions and apply her efforts. She took advantage of every option offered including individual therapy, which was not required legally. She rapidly demonstrated behaviors associated with gaining sobriety and regaining chemical baseline; including logical thinking pattern, improved impulse control and verbalization of personal responsibility. Then an undiagnosed malaise sabotaged her recovery effort. Eventually, she asked for attendance at the local ER. Fortunately the ER physician did not discharge with susupicions of drug seeking because of her CD history. The ER physician decided to order an electrocardiogram, which revealed pericarditis. Adequate treatment for the etiology of this client's malaise resulted in the completion of her treatment and long-term substance abstinence recovery. This client was one of the volunteers who left the State of her residence to help the survivors

J Mental Health Addic Nurs Vol 3(1):e32-e37; November 21, 2019. This article is distributed under the terms of the Creative Commons Attribution-Non Commercial 4.0 International License. OKaiser 2019. 
of hurricane Katrina. This choice to volunteer to aid victims of a natural disaster, at the considerable personal inconvenience, supports the assessment of sustained substance abstinence post-treatment. In contrast, continued substance misuse predictably would have rendered results of egocentric preoccupation to the point of lying to everyone (manipulation associated with $\mathrm{CD}$ ) to protect continued behaviors of substance misuse and to avoid consequences.

Conclusion: This example of the consistent and dedicated recovery effort, meeting standards of abstinence criteria with such a straight trajectory, regardless of medical problem and severity of addiction symptoms, at the commencement of treatment, is very rare. In the case of this client, these efforts were also accompanied by improvement with primary relationships to the client's mother and the client's son.

\section{CLINICAL RESPONSE TO “TURNING EAST”}

Urgent reports of emotional change should be taken seriously, and not be put-off. Clients asking for time to discuss their concerns need the immediate time or an appointment as soon as possible with competent and credentialed treatment personnel. Credentialed treatment personnel would also have the competence and willingness to discuss the spiritual concerns a patient presents. Spiritual concerns discussed should be those of the patient and without an attempt to "convert" to a particular belief system. It is often appropriate to refer the patient with spiritual needs to the pastor of their preference, or an official representative of their historical belief system.

\section{RESEARCH}

Spirituality has been accepted as a necessary part of recovery from addictions since the inception of AA., 4 And research has shown a positive correlation to AA attendance and post-treatment abstinence. ${ }^{9}$ In study one two different treatment groups were compared after receiving spiritual guidance during treatment. The first group of 60 participants randomly were assigned, or not assigned, a 12-session manual-guided spiritual intercession, during and after inpatient treatment.

Study two consisted of two 40-member cohorts receiving treatment as usual plus spiritual guidance, or without during inpatient stay. In both studies, the

J Mental Health Addic Nurs Vol 3(1):e32-e37; November 21, 2019.

This article is distributed under the terms of the Creative Commons Attribution-Non Commercial 4.0 International License. OKaiser 2019. use of spiritual guidance showed no positive effect on either spiritual practices or substance use outcomes. The spiritual guidance hypothesis expected to positively influence substance abuse reducing incidences of relapse by increasing spiritual functioning by three measures: daily spiritual experiences, meaning in life and private religious practices. Neither the spiritual guidance nor treatment as a usual group showed a significant change in measures. Follow-up of study at four-months showed the inverse effect of significantly less improvement on anxiety and depression measures, whereas the treatment as the usual group showed substantial improvement in anxiety and depression. Study results of depression, $[t(37)=-3.93$, $p<0.001\}$ and anxiety, $[t(37)=-3.95, p<0.001]$. One significant variable, identified by the authors of this study, was the timing of the spiritual intervention during the early recovery phase. The authors concluded that a more coordinated approach would be providing spiritual guidance after the initial period of stabilization. The authors also noted that spiritual development is a phenomenon, which occurs voluntarily over time with personal investment and may not be amenable to acute interventions to benefit organic disorders.

Another important factor of this study outcome is that over 12 months, three patients died. Causes of deaths were not cited in this research publication. ${ }^{5}$ These factors attest to the extreme peril and urgent needs of this population because deaths are frequent and often unexpected in the treatment of $\mathrm{CD}$ population.

Important conclusions cited by this research include: "(1) Spiritual formation is an individual and developmental process and may not be amenable to acute interventions, (2) Early recovery from addiction, if abstinence is maintained, includes a magnitude of changes, especially in early recovery or first 3-4 months. The authors recommend future studies are done after a period of stabilization and many other needs are addressed. (3) Substance abuse treatment has traditionally offered 28-day inpatient or outpatient treatment. This artificial timeline is very limited to hope to positively impact spiritual development, which is a lifelong process."

Studies by Schoenthaler about the correlation between sustained substance abstinence and high spirituality practices, or conversely low spirituality practices and 
higher relapse rates, yielded more expected results. ${ }^{6}$ The NIDA Drug Addiction Treatment Outcome Study was used to examine post hoc relapse rates of 2,947 clients interviewed at 12 months after intake, using five spirituality measures. Results of the Schoenthaler study indicated that those with low spirituality practices have higher relapse rates, and those with high spirituality practices have lower relapse rates, except for crack use. Over the five measures of spirituality tracked, a positive correlation with sustained abstinence was observed over the entire population study: function of strength of religious belief $\left(X^{2}=15.18, p=0.0280\right.$; logistic regression $=10.65, p=0.0060$ ); frequency of attending religious services $\left(X^{2}=40.78, p<0.0005\right.$; logistic regression $=30.45, p<0.0050)$; frequency of reading religious books $\left(X^{2}=27.190, p<0.0005\right.$; logistic regression $=17.31, p<0.0005)$; frequency of watching religious programing $\left(X^{2}=19.02, p=0.002\right.$; logistic regression $=\mathrm{ns})$; and frequency of meditation and prayer $\left(X^{2}=11.33, p=0.045\right.$; logistic regression= 9.650, $p=0.002$ ).

According to the conclusions of this research, " Much like the value of having a sponsor, for clients who abuse drugs, regular spiritual practice, particularly weekly attendance at the religious services of their choice, is associated with higher rates of remission." Accordingly, this research noted that these results demonstrate the clinically significant role of spirituality and the social bonds it creates. Those who developed social bonds via having a sponsor and attending weekly religious services had significantly higher rates of remission.

\section{CONCLUSION}

In the experience of this writer, working with the addiction population was both riveting and demanding. This author has encountered more deaths in attending the chemically dependent population, compared to the experience in all other treatment specialties combined, including medical/surgical, OR/Recovery Room, Public Health and psychiatry. The high incidence of death as an outcome for the chemical dependency population includes causes such as accidental overdose, suicide, violence from low-impulse control behaviors induced by substance abuse, car accidents, and many other reasons associated with violence and low-impulse control behaviors. Also, unidentified/untreated medical and dental conditions, associated with addiction and poor self-care, can subvert recovery efforts profoundly. ${ }^{1,7}$

Substance abuse is a chemically invasive process disrupting brain (neurological) function. The legal imposition of substance abstinence results in withdrawal with the goal of re-stabilization, which is accompanied by many neurological and chemical changes. Treatment clinicians need to be prepared to identify and respond to critical client needs as presented, which may include identifying substance withdrawal and assessing the risk of seizure/respiratory depression/cardiac events. ${ }^{7}$

As cited earlier in this writing, accomplishing attendance at group sessions, in addition to experiencing early prolonged withdrawal phase associated with brain chemistry changes reverting to brain chemistry baseline, is very demanding.

Often those personnel assigned to present the rationale and learning requirements, in outpatient treatment, are not equally prepared to attend to possible medical complications and emergencies resulting from withdrawal. This clinician has observed that most of the outpatient chemical dependency population has a history of poor medical and dental oversight ${ }^{8}$ and frequently malnutrition. ${ }^{1}$ Chemical dependency clients in treatment are mostly unaware of potential medical co-morbidities resulting from practices associated with substance misuse. All of these factors are potentially life-threatening.

In addition to these exceptional needs, the chemically dependent client population have many other needs associated with addiction, possibly interfering with treatment attendance and adherence, including childcare, transportation, unresolved conflict with family and/or support system and financial barriers, consequent of addiction behaviors, which compounds interference with treatment. Perhaps addressing all these potential factors, as indicated, and stricter regulation for the educational level of clinicians providing treatment would improve treatment outcomes. Advanced practice nurses making initial medical and psychiatric assessments and providing medication management for co-morbid conditions, and referrals, as indicated, is a treatment requirement change worth

J Mental Health Addic Nurs Vol 3(1):e32-e37; November 21, 2019.

This article is distributed under the terms of the Creative Commons Attribution-Non Commercial 4.0 International License. CKaiser 2019. 
consideration. The availability of advanced practice medical/psychiatric nursing personnel would ensure adequate response to emergencies related to withdrawal and other medical etiology. Adding access to social services to address transportation and childcare needs, would be another improvement worth implementing. Most of all, as cited prior, the clinician working with the chemically dependent population must always be prepared for the unexpected.

However, in agreement with research outcomes cited by the Miller research, ${ }^{5}$ this author is skeptical about any research process successfully capturing the spiritual response for scientific measurement and conclusion.

It is also important to note the factors referenced about treatment during the early recovery phase of substance abstinence. As has been cited many times in this writing, the first 90 days of substance abstinence includes many chemical changes. Brain dysfunction, induced by the addiction and continued during early abstinence of the first 90-days, includes behaviors of continued low impulse control, poorly regulated brain reward system and poor attention span. ${ }^{6,7}$ These typical neurological problems, during early abstinence, should improve with time. Still, the spiritual phenomenon of "Turning East" has been observed (by this author) during the early recovery phase of substance abstinence. The observation of "Turning East" is understood at this time (by this author) as not coming from the treatment process, and not originating from the intent of the treating clinician.

Statistical research, on the subject of spirituality and positive relationship to substance abuse abstinence, will enhance, and help identify and guide future treatment to more successful outcomes. Human spirituality may be the one aspect of substance abuse treatment in particular, and human life in general, that cannot be controlled for scientific study, because it does not exist in the material/organic realm and cannot be thus measured. In the context of this writing, human spirituality refers to a range of inner decisions regarding individual behavior responses, from a simple yes or no in response to a prompt or question, to the laying down of one's life for another.
Referring to the previous citation from Vatican $\mathrm{II},{ }^{2}$ this author, during group sessions, would often use the term, "personal dignity." There was never a question posed as to what this term meant. This writer would ask the group members if there were any questions about the meaning of the term "personal dignity." There were never any questions or requests for clarification, not once.

In being created in the image and likeness of God, each individual has personal dignity and absolute authority over the response of "yes or no" to inner spiritual promptings. It is appropriate to discuss this truth with links to consequences and personal responsibilities. This linking of personal dignity with personal choice and consequence is both logical and empowering to the client. This writer would often comment to treatment groups that everyone has absolute authority over personal choices, and not even God forces a response. The person is the only determinant of response to internal spiritual promptings, with the only possible response of either Yes or No. This repeated truth linked to choice/consequence was always met without question, or protest, from group members. Nowhere, in the experience of this clinician is this truth about personal choice and consequence-linked to personal empowerment more evident, and appropriate, then in the treatment of the $\mathrm{CD}$ population.

\section{REFERENCE}

1. Kaiser S. Psychiatric and adiction consultation for patients in critical care. Crit Care Nursing Clin North Am 2012;24(1):9-26.

2. Second Vatican Council. Pastorial Constitution on the Church in the Modern World, Gaudium et Spes. In Vatican Council II: The Conciliar and Post Conciliar Document; 1965.

3. Miller WR. Forcehimes AA, Zweben A. Treating addiction, a guide for professionals. New York, London: The Guilford Press; 2019.

4. Kurtz, E. A history of alcoholics anonymous. Center City, MN: Hazelden; 1987.

5. Miller WR. Forcehimes O'Leary M, and LaNoue M. Spiritual direction in addiction treatment: two clinical trials. J Sub Abuse Treat 2008;35(4):434-42.

J Mental Health Addic Nurs Vol 3(1):e32-e37; November 21, 2019.

This article is distributed under the terms of the Creative Commons Attribution-Non Commercial 4.0 International License. OKaiser 2019. 
6. Schoenthaler SJ, Blum K, Braveman ER, et al. NIDADrig Addiction Treatment Outcome Study (DATOS) relapse as a function of spirituality/religiousity. J Reward Defic Syndr 2015;1(1):36-45.

7. Kaiser S, Prendergast K, Ruter TJ. Nutritional links to siubstance abuse recovery. J Addiction Nurs 2008;19(3):125-29.
8. Kaiser S. The Importance of oral health in the treatment outcomes for the chemically dependent population. Alcoholism Drug Depend 2015;3(3).

9. Emrick CD, Tonigan JS, Montgomery H, Little L. Alcoholics Anonymous: What is Currently Known? New Brunswick, NJ: Rutgers Center of Alcoholic Studies; 1993.

J Mental Health Addic Nurs Vol 3(1):e32-e37; November 21, 2019.

This article is distributed under the terms of the Creative Commons Attribution-Non Commercial 4.0 International License. OKaiser 2019. 